\title{
Combined aortic arch repair and arterial switch without coronary reimplantation
}

\author{
Kozo Ishino, MD, Masaaki Kawada, MD, Ko Yoshizumi, MD, and Shunji Sano, MD, Okayama, Japan
}

T he arterial switch procedure is a widely used approach for the surgical management of double-outlet right ventricle of the Taussig-Bing type. This malformation is often associated with muscular subaortic stenosis and aortic arch obstruction (AAO), resulting in a marked discrepancy between the hypoplastic ascending aorta and the dilated main pulmonary artery (PA). In addition, variations in coronary artery anatomy are not uncommon. ${ }^{1}$ To avoid all of these difficulties in a standard switch operation, we developed a combined procedure of aortic arch reconstruction and an arterial switch without coronary reimplantation; it has been performed in 2 patients with Taussig-Bing hearts with coarctation of the aorta.

\section{Clinical Summaries}

Patient 1 (17 days old; $3.3 \mathrm{~kg}$ ) and patient 2 (27 days old; $2.6 \mathrm{~kg}$ ) had subpulmonary ventricular septal defects with $100 \%$ overriding of the PA and a side-by-side relationship of the great arteries with a bilateral subarterial conus. The diameters of the ascending aorta and the main PA were 6 and $13 \mathrm{~mm}$, respectively, in patient 1 and were 7 and $13 \mathrm{~mm}$, respectively, in patient 2 . In patient 1 , a single coronary artery arose from the posterior (right)-facing sinus, and a small infundibular branch originated from the anterior (left)-facing sinus. In patient 2 , the posterior-facing sinus gave rise to an artery that divided into the right coronary and the circumflex coronary arteries, and the anterior-facing sinus gave rise to the anterior descending coronary artery, but both orifices were close to the hinge point of the aortic leaflets.

After a median sternotomy, cardiopulmonary bypass was instituted with dual arterial cannulations: one was placed into the innominate artery, and the other was introduced into the descending aorta via the ductus arteriosus. With the rectal temperature at $25^{\circ} \mathrm{C}$, the heart was arrested by cold crystalloid cardioplegia, and the ventricular septal defect was closed with a patch through a right ventriculotomy. The neck vessels were snared, and the innominate artery was perfused to maintain cerebral circulation. Both great arteries were transected at the level of the pulmonary

From the Department of Cardiovascular Surgery, Okayama University Graduate School of Medicine and Dentistry, Okayama, Japan.

Received for publication Sept 2, 2003; revisions requested Sept 30, 2003; accepted for publication Oct 16, 2003.

Address for reprints: Kozo Ishino, MD, Department of Cardiovascular Surgery, Okayama University Graduate School of Medicine and Dentistry, 2-5-1 Shikata-cho, Okayama-City 700-8558, Japan (E-mail: ishino@tb3.sonet.ne.jp).

J Thorac Cardiovasc Surg 2004;127:577-8

$0022-5223 / \$ 30.00$

Copyright $\odot 2004$ by The American Association for Thoracic Surgery

doi:10.1016/j.jtcvs.2003.09.037 bifurcation (Figure 1, A). The descending aortic cannula was removed, and ductal tissue was excised. The aortic arch was completely opened down to the ascending aorta, thereby making an aortic flap (Figure 1, B). The wall of the proximal ascending aorta and adjacent PA wall were cut in a $\mathrm{U}$ shape and were sutured together. An incision was made in the anterior wall of the aortic root, extending into the right ventricular outflow tract. The aortic valve commissure between the facing sinuses was then detached so that both coronary ostia emptied into 1 sinus. After a Lecompte maneuver, the back wall of the descending aorta was anastomosed to the posterior wall of the aortic arch (Figure 1,C). The proximal main PA was anastomosed to this confluence, and the anastomosis was extended approximately two thirds of the way out of the ascending aorta. The proximal end of the aortic flap was sutured to cover both coronary ostia, thereby creating an aortopulmonary window and a tunnel between the neoaorta and the coronary ostia (Figure 1,D). The posterior wall of the pulmonary bifurcation was then anastomosed to the proximal neo-PA, thus incorporating the superior aspect of the aortic tunnel. Finally, the anterior wall of the neo-right ventricular outflow tract was covered with an autologous pericardial patch with a monocuspid valve (Figure 1,E).

Both infants had an uneventful postoperative recovery, with no evidence of myocardial ischemia. At the age of 1 year, patient 2 underwent elective cardiac catheterization, which demonstrated no pressure gradient across the arch anastomosis and an unobstructed coronary pathway from the neoaorta through the surgically created aortopulmonary window (Figure 2).

\section{Discussion}

Reconstruction of the aorta is a key component to a successful one-stage repair of the Taussig-Bing heart with AAO. Planché and colleagues ${ }^{2}$ repaired the aortic arch by an extended end-to-end anastomosis in 14 patients, but 3 of them required patch augmentation of the distal aorta to accommodate a neoaortic anastomosis. Liddicoat and colleagues ${ }^{3}$ developed an aortic relocation technique, in which a new aortic arch was reconstructed by anastomosing the proximal ascending aorta to the descending aorta, followed by anastomosis of the neoaorta to the underside of the new aortic arch. Tchervenkov and associates ${ }^{4}$ used a pulmonary homograft patch to enlarge the entire aortic arch and distal ascending aorta. We have reconstructed the aorta by direct anastomosis of both the descending aorta and the neoaorta to the opened-out aortic arch without patch supplementation.

In the case of complex coronary anatomy coupled with widely disparate great arteries, the coronary translocation required for the arterial switch is a formidable surgical challenge. Therefore, we accomplished arch reconstruction and the arterial switch without coronary relocation by creating an internal tunnel with the flap of the distal ascending aorta. This rerouting procedure, which uses the aortic wall for partitioning, was first introduced by Takeuchi and Katogi ${ }^{5}$ in 1990. Although the long-term outcome of this 

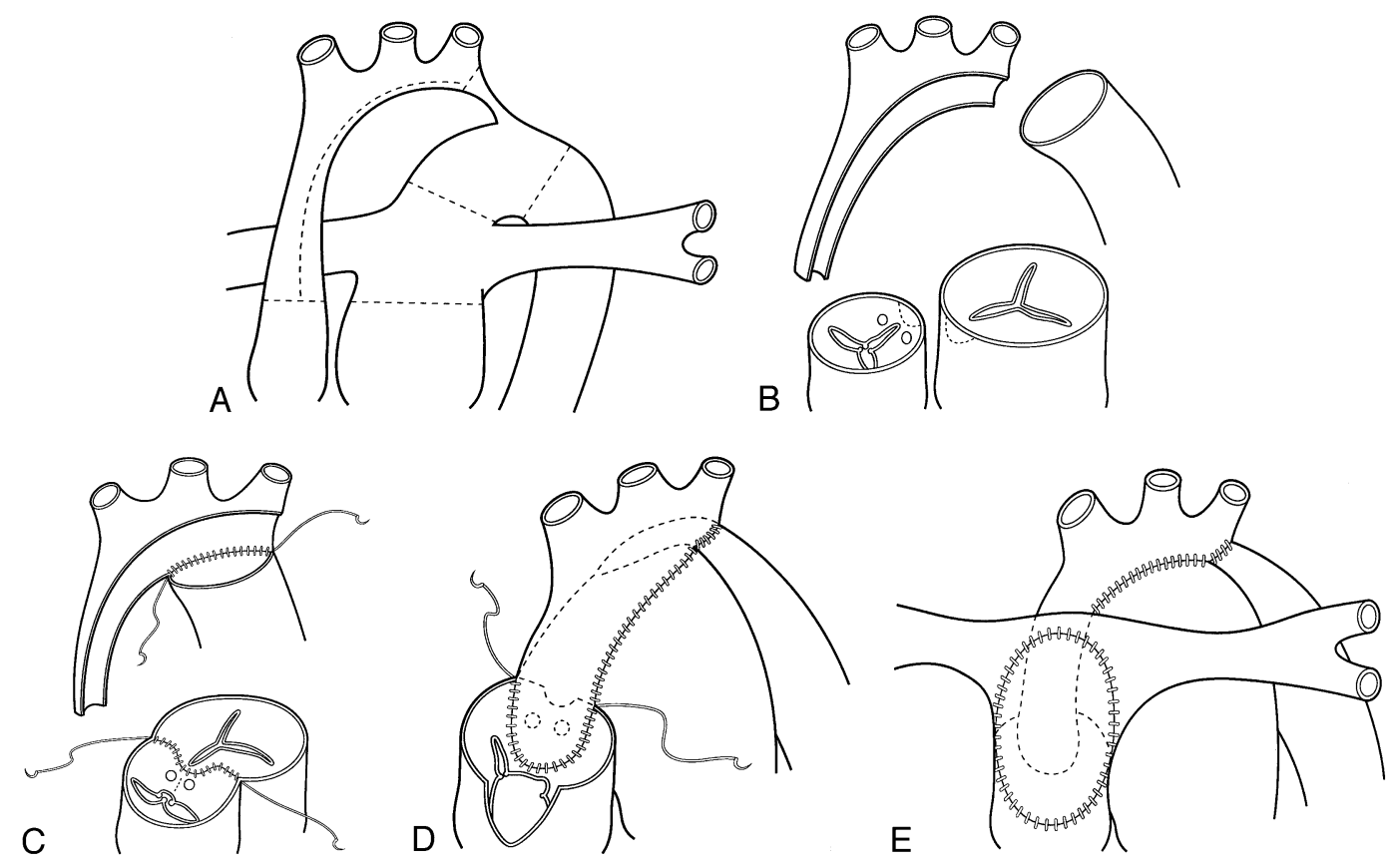

Figure 1. A, Taussig-Bing heart with coarctation of the aorta. B, Transection of the great arteries, ductus arteriosus, descending aorta, and aortic arch and the aortotomy from the aortic arch to the distal ascending aorta. C, Creation of the aortopulmonary window and anastomosis of the descending aorta to the posterior wall of the aortic arch. D, Anastomosis of the neoaorta to the aortic arch and rerouting of the coronary arteries. $E_{\text {, }}$ Reconstruction of the neo-right ventricular outflow tract after a Lecompte maneuver.

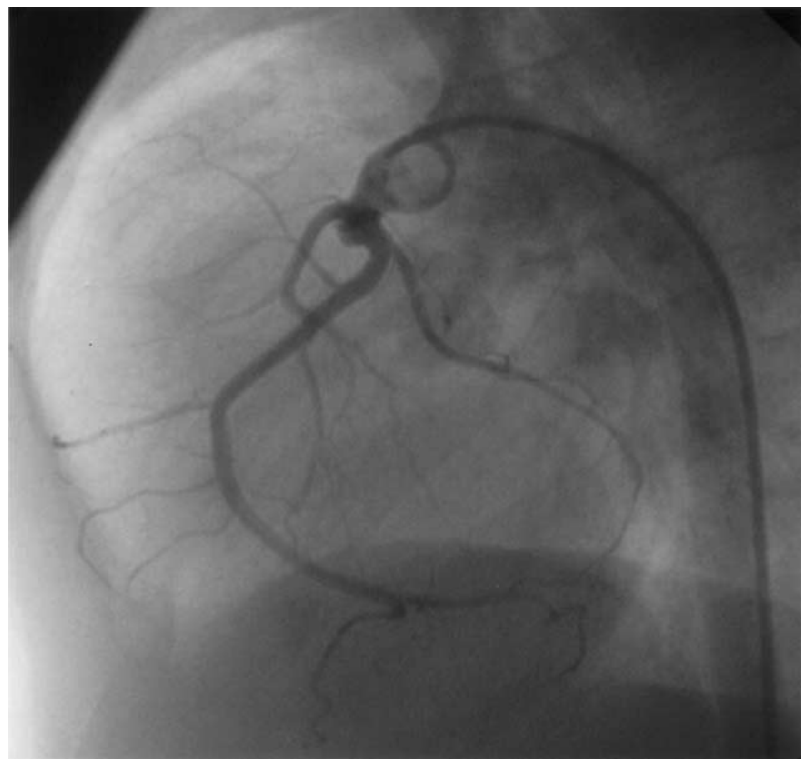

Figure 2. Aortogram 1 year after the combined aortic arch repair and arterial switch in patient 2 , showing good coronary perfusion through the internal tunnel. procedure in terms of ensuring coronary arterial flow is unknown, angiography in the second child at 1 year was encouraging. Thus, we believe that the operative technique described here is useful for one-stage repair of Taussig-Bing heart with AAO, when direct transfer of the coronary ostia without producing tension or kinking is technically difficult.

\section{References}

1. Uemura H, Yagihara T, Kawashima Y, Nishigaki K, Kamiya T, Ho SY, et al. Coronary arterial anatomy in double-outlet right ventricle with subpulmonary VSD. Ann Thorac Surg. 1995;59:591-7.

2. Planché C, Serraf A, Comas JV, Lacour-Gayet F, Bruniaux J, Touchot A. Anatomic repair of transposition of great arteries with ventricular septal defect and aortic arch obstruction. J Thorac Cardiovasc Surg. 1993;105:925-33.

3. Liddicoat JR, Reddy VM, Hanley FL. New approach to great-vessel reconstruction in transposition complexes with interrupted aortic arch. Ann Thorac Surg. 1994;58:1146-50.

4. Tchervenkov CI, Tahta SA, Cecere R, Béland MJ. Single-stage arterial switch with aortic arch enlargement for transposition complexes with aortic arch obstruction. Ann Thorac Surg. 1997;64:1776-81.

5. Takeuchi S, Katogi T. New technique for the arterial switch operation in difficult situations. Ann Thorac Surg. 1990;50:1000-1. 